\title{
IS NOTICING AN ANSWER TO THE PROBLEM OF UNACQUIRABLE STRUCTURES IN THE SECOND LANGUAGE?
}

\author{
Frenette Southwood, Stellenbosch University
}

\section{INTRODUCTION}

The aim of this article is to evaluate one proposed solution to the problem that some aspects of a second language (L2) seem unacquirable. In order to understand the solution, it is necessary to explicate the problem. This will be done by providing a brief description of Fodor's (1983) modular view of the human mind, followed by an account of the views of two researchers on second language acquisition (SLA), namely that of Krashen (whose view is compatible with the modular view of the human mind) and that of White (whose view is not). These two researchers agree on many aspects of SLA, but disagree about whether learnt knowledge of language can become acquired knowledge. It is here that an interesting question arises, namely the question of whether certain aspects of an L2 can be learnt, but not acquired. One proposed answer to this problem, namely that of noticing, will be evaluated. Reasons why noticing is, at present, more of a problem than an answer will be provided, and a case will be made for the Noticing Hypothesis being testable in theory but not in practice.

\section{MODULES OF THE MIND}

According to Fodor (1983), human cognitive processes can be divided into two types of systems or modules. ${ }^{1}$ The first type is domain-specific and autonomous. This means that their functioning does not influence that of the other cognitive processes, but that each module is dedicated to its own kind of processing of a specific type of information. One such domainspecific module is the language module. The second type of cognitive system is more general and receives as input the output of the domain-specific systems. One such general system is the central processing (CP) module which contains, inter alia, general learning mechanisms and general problem-solving skills. 
Language use results from the processing of information by the CP module. This information is produced and fed into it by the language module (and other modules). This process is not reversible. Therefore, the language module (being dedicated to knowledge of language and to no other types of knowledge) can process only a certain kind of information, and information from the CP module does not qualify. To quote Schwartz (1993:156), "[1]anguage input can be dealt with solely in the language module, and this is the only thing that the language module does."

\section{KRASHEN'S VIEW ON SECOND LANGUAGE ACQUISITION}

One view on SLA that is compatible with the modular view of the mind, is that of Krashen (see, for example, Krashen 1981, 1985). In summarized (and simplified) form, his view on SLA is as follows: L2 learners bring to the task of SLA their language acquisition device (LAD). Krashen is not at all clear on what this LAD comprises, but it is widely assumed to consist of the learner's natural language acquisition abilities. ${ }^{2}$ On Krashen's view, the LAD is unaltered by the fact that the L2 learner has already used this very same LAD to acquire at least one other language, viz. the learner's first language (L1).

According to Krashen, there are only two prerequisites for successful SLA. The first prerequisite is comprehensible input, i.e. input that contains structures that are "a bit beyond our [the L2 learner's - FS] current level of competence" (Krashen, 1985:2). The second prerequisite for successful SLA is a low affective filter. The affective filter is made up of affective, social, and/or psychological factors, such as anxiety, and acts as a barrier that can be "down", allowing input to reach the LAD, or "up", preventing input from reaching the LAD, and so preventing language acquisition.

According to Krashen, the learner has two independent means of developing ability in the L2. By "independent" is meant that these means are the result of separate kinds of input, and that the specific kind of knowledge that each produces remains separate; one kind of knowledge can never be converted into the other. The first way of developing L2 knowledge, namely that of acquisition, is a subconscious process that takes place incidentally (i.e. without conscious effort and without the learner focusing on form) as a result of natural input reaching the LAD. 
The second way, namely that of learning, is a conscious process that takes place intentionally through the learner heeding formal instruction in the L2. According to Krashen's view, it is impossible to convert learnt knowledge into acquired knowledge. Rather, learnt knowledge acts as an editor or monitor: After a potential utterance is generated by the acquired knowledge in the LAD, the learnt knowledge makes the necessary corrections before the utterance is spoken or written.

Krashen's view on SLA is compatible with the modular view of the human mind, because both claim that information generated by the language module (by which L2 knowledge is acquired) serves as input for the CP module (containing the general learning mechanisms with which learnt knowledge is obtained). ${ }^{3}$

\section{WHITE'S VIEW ON SECOND LANGUAGE ACQUISITION}

According to White, the L2 learner brings to the task of SLA universal principles with their parameters set to the L1 values. Where the L1 and L2 parameter values are similar (e.g. where both require the case assigner and its complement to be adjacent to one another), no resetting of parameters needs to take place. However, where L2 learners gather from evidence in the input that the L1 parameter value (e.g. [-strict adjacency]) is incorrect for their L2 (which is a [+strict adjacency] language), that parameter needs to be reset. ${ }^{4}$

On White's (1990) view, there are cases in which natural input (also known as communicative input) is insufficient for triggering such parameter resetting. One such case is where learners need evidence that a structure that is grammatical in their L1, is not possible (is ungrammatical or cannot occur) in the L2. According to White $(1990 / 1,1991)$, for SLA to be successful (i.e. for parameters to be set to the correct L2 values), the L2 learner needs both positive evidence (which is evidence that a structure can occur in the L2) that occurs in natural input, and negative evidence (which is evidence that a structure cannot occur in the L2, or that a structure cannot be interpreted in the same way in the L2 as in the L1). One case in point would be where a Japanese learner of English needs evidence that Abel thinks Cain misleads himself can only be interpreted as "Abel thinks Cain misleads Cain", whereas in 
Japanese the sentence could be interpreted as either "Abel thinks Cain misleads Cain" or "Abel thinks Cain misleads Abel".

Because negative evidence is not present in natural input, the non-occurrence of a structure in the L2 that does occur in the L1 needs to be pointed out to the L2 learner before (on White's view) certain parameters can be reset. According to White (1989:168), this "pointing out" can take the form of grammar teaching, error correction or consciousness-raising, the latter to which will be returned later. The notion of resetting parameters (seated in the language module) with the aid of consciously learnt knowledge (the result of using general learning mechanisms seated in the CP module, and thus lying outside the language module) is incompatible with the modular view of the human mind. Recall that this view holds that the language module cannot process the kind of information produced by the $\mathrm{CP}$ module. To restate in Krashen's terms: Learnt knowledge (learning that a structure cannot occur in the L2, by being made aware of its non-occurrence) cannot be converted to acquired knowledge (involving parameter resetting, according to White). ${ }^{5}$

\section{ACQUIRED (AND ACQUIRABLE) VS. LEARNT KNOWLEDGE}

If the modular view of the human mind is correct, it seems as though some aspects of the L2 (those that do not occur in natural input and, therefore, necessitate negative evidence) can never be acquired but can only be learnt. The question arises whether certain parameters can then ever be set to the correct L2 values. ${ }^{6}$ A very limited number of solutions have been offered, one of them being noticing (proposed by e.g. Le Roux, 1994:27-28). Before turning to the discussion of noticing, it should be explained why it is preferable for structures to be acquired rather than learnt. According to Krashen (1985:2), at least two conditions must be met in order for learnt knowledge to effectively monitor potential utterances generated by the acquired knowledge. The first is that the learner must be consciously concerned about the correctness of his/her production. The second condition is that the learner must know the grammatical rule concerned. (A third condition, namely sufficient time to think about and use conscious rules, was originally specified, but this condition has now proved to be nonfundamental - see Krashen 1985:22.) If these conditions are not met, incorrect utterances will be produced, should any structure in the utterance not have been acquired. However, if 
utterances are produced by acquired knowledge, they are more likely to be correct. Although factors such as fatigue can still cause an utterance to incorrectly "reflect" competence, the above-mentioned two (previously three) factors do not affect the accuracy of utterances generated by acquired knowledge.

\section{NOTICING AS A SOLUTION}

One proposed solution to the apparent unacquirability of certain L2 structures (henceforth, problem structures) is making the learner sensitive to the problem structure without explicitly teaching the structure (so as to prevent the learner from learning the structure by using the general learning mechanisms of the $\mathrm{CP}$ module). This process is referred to as input enhancement by, inter alia, Sharwood Smith (1993:165) and as consciousness-raising by, inter alia, Fotos (1993:386). After sensitization, the learner would presumably remain aware of this structure and "spot" it (or its absence) in subsequent natural input. As interaction with natural input leads to acquisition, and not to learning, the L2 learner would then, after all, be able to acquire problem structures from natural input (and to reset parameters, on White's view).

One mechanism used to "spot" problem structures after sensitization, is noticing. Schmidt (1990) proposed what Truscott (1998:103) calls the "Noticing Hypothesis", which claims that L2 learners must consciously notice the form of their L2 input in order for the input to become intake, i.e. in order for the input to lead to acquisition of grammar. This does not only apply to grammatical form, but to phonology, the lexicon, and pragmatics as well (Schmidt 1990:149). ${ }^{7}$

Ellis (1994a:94) discusses a number of factors that may cause learners to notice certain features in the input. Included in the list are (i) the demands of the instructional task (in cases where the task cannot be completed without noticing the features), (ii) frequency of the features in the input, (iii) features that do not conform to the expectations of the learner (i.e. unusual features in the input), (iv) salience of features as a result of their position in the sentence or of their phonological form, and (v) the learner's existing linguistic knowledge (causing the learner to notice certain features before others). According to Fotos (1993:386), it 
is essential for learners to notice features in natural input after being made aware of them, because noticing is a prerequisite for language processing, the latter leading to the eventual acquisition of the structure. ${ }^{8,9}$

\section{THE TESTABILITY OF THE NOTICING HYPOTHESIS}

Although the occurrence of noticing seems reasonable when explained as it is above, it is, in fact, problematic. The main reason for this is that noticing and what it supposedly leads to (namely acquisition and not learning) cannot and, therefore, has not, been researched to any satisfactory degree, because the Noticing Hypothesis is testable in theory, but not in practice. This distinction between testability in theory and testability in practice is made by Hemple (1966).

\subsection{The testability in theory of the Noticing Hypothesis}

According to Popper (1969:36), testability equals refutability. By this he means that refutability is a necessary condition for empirical status. A hypothesis that is confirmable but not refutable, is, according to Popper, not an empirical hypothesis. To accommodate Popper's view, Hemple's (1966:30) original definition of testability can be amended to the following: A hypothesis is testable in theory if precise test implications can be derived from the hypothesis, and if it is possible to specify what experimental findings, should they be available, would indicate whether the test implications of the hypothesis are false.

The Noticing Hypothesis predicts that certain forms in the L2 input will be converted into intake if an L2 learner notices the form of the input. If one divorces the content of this hypothesis from the controversial notions of attention and conscious learning, to which noticing is related, then precise test implications can be derived from the Noticing Hypothesis. These implications are:

(i) If an L2 learner pays attention to and notices a certain form in the L2 input, then the learner will acquire that form.

(ii) If an L2 learner does not pay attention to and notice a certain form in the L2 input, then the learner will not acquire that form. 
(iii) If a form has been acquired by an L2 learner, then that learner previously paid attention to that form and noticed it.

\subsection{The testability in practice of the Noticing Hypothesis}

According to Hemple (1966:30), a hypothesis is testable in practice if precise test implications can be derived from the hypothesis, and if experimental findings which would indicate whether the test implications of the hypothesis are true or false, are in fact available. It has been shown that precise test implications can be derived from the Noticing Hypothesis. In the remainder of this article, it will be shown that certain empirical problems render results of studies on noticing uninterpretable, thus making unavailable experimental findings, which would indicate whether the test implications of the Noticing Hypothesis are true or false.

Before considering the empirical problems, a research design that may be used (and has been used by, inter alia, Fotos, 1993) to establish whether noticing occurs, will be described: In such a design, three groups of participants are needed, all without (conscious or unconscious) knowledge of the problem structures in question. One group acts as a control, receiving no formal grammar instruction, but receiving communicative input that has not been altered to ensure a high frequency of occurrence of the problem structures. The two test groups both focus on the structures, one (the grammar lesson group) receiving formal teacher-fronted instruction, and the other (the grammar task group) performing a grammar consciousnessraising task that draws the participants' attention to the problem structures. Either on-line or post-task/post-lesson (henceforth, post-treatment) measurements may be performed to test for noticing. On-line measures may include check-marking certain grammatical structures while listening to oral input, producing think-aloud protocols during a reading task, taking notes, and underlining certain grammatical structures embedded in written texts. Post-treatment measures may include multiple choice recognition tasks, grammaticality judgements, and debriefing interviews or questionnaires conducted after treatment (Izumi and Bigelow, 2000:241). Although on-line measurements cannot claim to tap all of the L2 learners' attention processes, they have an advantage over post-treatment measurements in that the online measurements access the L2 learners' ongoing internal processes more directly and so 
minimize possible memory loss (Izumi and Bigelow, 2000:241). Below, five empirical problems with research on noticing will be discussed.

\section{a. Selecting research participants}

The first problem with research on noticing concerns selecting research participants. If one sets out to determine whether a problem structure is noticed by a participant after he/she has been sensitized to it, one has to eliminate the possibility of the participant having acquired or learnt that structure prior to inclusion in the study. In order to establish this, some form of screening or pre-testing needs to take place, with the pre-test (presumably) containing instances of the problem structure. This poses a problem, because, by exposing participants to the structure during screening, one might even in the pre-treatment stage be influencing them to notice the structure in the post-treatment input. The role of the pre-test and that of the task or lesson in bringing about noticing will, therefore, not be separable.

\section{b. Pre-testing the control group}

The problem stated in the previous subsection is particularly complex in the case of the control group, the group that will not have their attention directed to the problem structure. If the researcher decides not to pre-test the participants in the control group in order not to sensitize them in any way, one might experience difficulty in interpreting the findings. Should the results show that the control group noticed the structure during post-treatment testing, one would not know whether they had learnt or acquired the structure even before the research study, or whether they had no knowledge of the structure before the commencement of the study, but noticed it without having been sensitized to it.

\section{c. Frequency of problem structures in sensitization material}

Two questions arise regarding the consciousness-raising task of the grammar task group. The first question concerns the frequency with which the problem structure should occur in the task in order to result in sensitization, and how one will establish this frequency. ${ }^{10}$ The second question concerns what happens if the minimum occurrence requirement is not met. In such a case, the researcher could be misled to assume that sensitization tasks are being performed while, in fact, the tasks happen to be no more effective than "ordinary" natural input. Under- 
using the problem structure in the grammar consciousness-raising task, therefore, leads to difficulties in interpreting results.

\section{d. Proving that a structure has been acquired and not learnt}

An often-mentioned problem in linguistic research is that researchers use behavior (such as production data or grammaticality judgements) to make inferences about the nature of the content of the human mind and, specifically, of the language module. ${ }^{11}$ In research on noticing, this problem becomes even more complex, as the researcher wants to know not only whether the learner has knowledge of a certain structure, but also whether this knowledge was acquired (subconsciously) or learnt (consciously). Few activities or behavior tests are presently able to reveal the difference between learnt and acquired knowledge.

Schwartz (1993:154-55) suggests one method of distinguishing between learnt linguistic knowledge and "real" competence. The first step in this method is to identify two languages that differ in one aspect of grammar, or one parameter. In the one language, the L1 of a particular group of speakers, two constructions (X and Y) are both possible and both follow from some specific property of the grammar, presumably, because $\mathrm{X}$ and $\mathrm{Y}$ are linked to a certain parameter setting. In the L2 of these speakers, this specific property of the grammar does not pertain, because the relevant parameter setting differs from that instantiated in the L1, and, therefore, both constructions $\mathrm{X}$ and $\mathrm{Y}$ are ungrammatical. The second step in this method is to demonstrate that the L2 learners initially incorrectly assumed that both $X$ and $Y$ were indeed possible in the L2. The third step is to provide these L2 learners with negative evidence on one construction, and then test whether knowledge about the impossibility of the other construction automatically follows. According to Schwartz, a distinct finding will have been made if the speakers end up with knowledge of only what they have been taught. This finding would be that, although their L2 behavior has been changed due to them learning of the impossibility of X, their L2 grammar (or competence) has not been affected. If the results do indicate that their L2 grammar has not been affected, this method would be one way to distinguish L2 acquisition from learning in a principled fashion.

If the results do indicate whether the speakers' competence has been affected or not, then researchers do need to find a way of determining whether a structure was learnt during the 
sensitization process and then noticed as a result of being learnt, because the claim is that noticing ultimately leads to acquisition, not to learning. Should noticing then be the result of learning and not the precursor to acquisition, the purpose of sensitization needs to be reconsidered.

\section{e. The time span between sensitizing, noticing and acquisition}

The fifth problem with research on noticing concerns the time span between sensitizing to, noticing and acquisition of a structure. This problem is discussed by Truscott (1998:118-19), who concludes that many studies on noticing did not include follow-up testing for the longterm effects of noticing, that those studies which did, performed retesting after a delay of five weeks or often much less, and that none of these studies provided evidence for the benefit of form-focused teaching. The question arising from these studies concerns the time span for which a L2 learner needs to notice a structure before language processing (that leads to acquisition) takes place, i.e. how soon acquisition should be tested for. Another question concerns whether it is possible to test for noticing after a long delay, as the learner might have learnt the structure by other means between the time of sensitization and the time noticing is tested for. ${ }^{12}$

\section{CONCLUSION}

Le Roux (1994:27) states that, if the modular view of the human mind is held to be accurate, then Krashen is correct in stating that learnt knowledge cannot become acquired knowledge. Furthermore, if certain grammatical structures of an L2 cannot be deduced from natural input, then White (1998) is correct in stating that negative evidence is needed for successful SLA. However, negative evidence leads to learnt knowledge. From this it can be concluded that certain aspects of the L2 are unacquirable.

Noticing is one proposed solution to this problem of the apparent unacquirability of certain aspects of the L2. In this article, it has been shown that certain considerations cause the Noticing Hypothesis not to be testable in practice. 
Despite empirical problems, previous studies on noticing were not in vain. The results of these studies have led researchers to interesting temporary conclusions, such as that using carefully planned grammar tasks (that learners find enjoyable) can be as effective as formal, traditional grammar instruction (although some studies show that neither contributes directly to successful SLA). What results of research on noticing could not show, was whether noticing did in fact take place, and whether any gains in post-treatment results could, with reasonable certainty, be ascribed to noticing. 


\section{NOTES}

${ }^{1}$ See (Botha 1989: par. 2.7.3) for a discussion of Noam Chomsky's view on the modularity of the human mind.

${ }^{2}$ See McLaughlin (1987:23-24) for a comparison of Krashen's and Chomsky's (the originator of the concept) LAD. Note that the relationship between "Krashen's" LAD and Universal grammar (UG) is not clear. According to some researchers, the LAD and UG are similar; according to others, UG forms a part of the LAD, because the LAD also contains learning principles and processing mechanisms (White, in press).

${ }^{3}$ See Krashen (1985:chapters 1 and 2) for a detailed account of Krashen's view on SLA, or see Cook (1993:51-55) for a briefer account. McLaughlin (1987:chapter 2) contains a thorough discussion and critique of Krashen's hypotheses.

${ }^{4}$ This view of White is not without its critics. See Cook $(1993: 207)$ for a brief outline of White's and opposing views on the initial parameter values. Also see White (1989:chapter 6) for a detailed discussion of views that oppose hers. Tsimpli and Roussou (1991) provide a further view that opposes White's.

${ }^{5}$ Note, however, that, on White's 1998 view, there is no limitation on the kind of input that can "drive" Universal Grammar in SLA; see Schwartz, 1993:153, for a brief discussion. White's (personal communication) current stance is that, even when L2 learners receive negative input, they cannot make use of this input for parameter resetting. In other words, White now claims that there may be a limitation on the kinds of input that can engage UG, and that negative input is one type of input that cannot engage UG.

${ }^{6}$ A related issue, that will not be discussed here, is that some L2 learners may not receive the relevant positive input necessary for parameter resetting.

${ }^{7}$ See Truscott (1998) for a discussion on the strong and weak forms of this hypothesis.

${ }^{8}$ Fotos (1993:386) does not explicate this statement.

${ }^{9}$ Also, on White's (in press) view, the L2 learner must notice what she calls "triggers" (i.e. some property of the input) in the input before the learner can use the input to reset parameters. However, White states that the learner will notice the triggers when his/her grammar is ready, and not necessarily when someone attempts to make him/her aware of these triggers. 
${ }^{10}$ See Ellis (1994b:269-273) for a summary of various studies on input frequency and accuracy in acquisition.

11 See Botha (1989:47-51) for a discussion of, among other (related) things, Chomsky's distinction between behavior as evidence $v s$. behavior as criterion for the possession of language knowledge.

12 See (White 1990/1) in which learners were exposed to negative evidence on adverb placement or question formation. Test results obtained immediately after the exposure to the evidence seemed to indicate that learners used the negative evidence to reset the parameter, but the post-test results obtained one year later revealed that the learners had apparently "lost" the knowledge. This led Schwartz and Gubala-Ryzack (1992) as well as White (personal communication) to conclude that the knowledge displayed immediately after exposure to negative evidence was learnt linguistic knowledge and that the parameter was not reset. 


\section{REFERENCES}

Botha, R.P. 1989. Challenging Chomsky. The generative garden game. Oxford: Basil Blackwell.

Cook, V. 1993. Linguistics and second language acquisition. London: The Macmillan Press Limited.

Ellis, R. 1994a. A theory of instructed second language acquisition. In N.C. Ellis (ed.) Impact and explicit learning of languages. London, etc.: Harcourt Brace and Company.

Ellis, R. 1994b. The study of second language acquisition. Oxford: Oxford University Press.

Fodor, J.A. 1983. Modularity of mind. Cambridge, Mass.: MIT Press.

Fotos, S.S. 1993. Consciousness raising and noticing through focus on form: grammar task performance versus formal instruction. Applied Linguistics 14: 385-407.

Hemple, C.G. 1966. Philosophy of natural science. Englewood Cliffs, N.J.: Prentice-Hall Inc.

Izumi, S, and M. Bigelow. 2000. Does output promote noticing and second language acquisition? TESOL Quarterly 34: 239-78.

Krashen, S. 1981. Second language acquisition and second language learning. Oxford: Pergamon.

Krashen, S.D. 1985. The Input Hypothesis: Issues and implications. London and New York: Longman.

Le Roux, C. 1994. Modular minds and input in second language acquisition. SPIL PLUS 26: $17-35$.

McLauglin, B. 1987. Theories of second-language learning. London: Edward Arnold.

Popper, K.R. 1969. Conjecture and refutations. The growth of scientific knowledge ( $3^{\text {rd }}$ ed.) London: Routledge and Kegan Paul.

Schmidt, R.W. 1990. The role of consciousness in second language learning. Applied Linguistics 11: 129-58.

Schwartz, B.D. 1993. On explicit and negative data effecting and affecting competence and linguistic behavior. Studies in Second Language Acquisition 15: 147-63.

Schwartz, B.D. and M. Gubala-Ryzack. 1992. Learnability and grammar organization in L2A: against negative evidence causing the unlearning of verb movement. Second Language Research 8(1):1-38. 
Sharwood Smith, M. 1993. Input enhancement in instructed SLA. Theoretical bases. Studies in Second Language Acquisition 15: 165-79.

Truscott, J. 1998. Noticing in second language acquisition: a critical review. Second Language Research 12: 103-35.

Tsimpli, I-M. and A. Roussou. 1991. Parameter-resetting in L2? UCL Working Papers in Linguistics 3: 149-69.

White, L. 1989. Universal Grammar and second language acquisition. Amsterdam: John Benjamins Publishing Company.

White, L. 1990. Implications of learnability theories for second language learning and teaching. In M.A.K. Halliday, J. Gibbons, and H. Nicholas (eds.) Learning, keeping and using language. Amsterdam: John Benjamins Publishing Company.

White, L. 1990/1. The verb-movement parameter in second language acquisition. Language acquisition 1(4): 337-360.

White, L. 1991. Adverb placement in second language acquisition: Some effects of positive and negative evidence in the classroom. Second language research 7: 133-61.

White, L. (in press). Second language acquisition and Universal Grammar. Cambridge, Mass.: Cambridge University Press. 